Pacific Journal of Mathematic 


\title{
ON $(\mathfrak{m}-\mathfrak{n})$ PRODUCTS OF BOOLEAN ALGEBRAS
}

\author{
R. H. LA Grange
}

This discussion begins with the problem of whether or not all $(\mathfrak{m}-\mathfrak{n})$ products of an indexed set $\left\{\mathfrak{U}_{t}\right\}_{t \in T}$ of Boolean algebras can be obtained as m-extensions of a particular algebra $\mathscr{F}_{\mathfrak{n}}^{*}$. The construction of $\mathscr{F}_{\mathfrak{n}}^{*}$ is similar to the construction of the Boolean product of $\left\{\mathfrak{U}_{t}\right\}_{t \in T}$; however the $\mathscr{A}_{t}$ are embedded in $\mathscr{F}_{\mathfrak{n}}^{*}$ in such a way that their images are $\mathfrak{n}$-independent. If there is a cardinal number $\mathfrak{n}^{\prime}$, satisfying $\mathfrak{n}<\mathfrak{n}^{\prime} \leqq \mathfrak{m}$, then $\left(\mathfrak{m}-\mathfrak{n}^{\prime}\right)$ products are not obtainable in this manner. For the case $\mathfrak{n}=\mathfrak{m}$ an example shows the answer to be negative. It is explained how the class of m-extensions of $\mathscr{F}_{\mathfrak{n}}^{*}$ is situated in the class of all $(\mathfrak{m}-\mathfrak{n})$ products of $\left\{\mathfrak{U}_{t}\right\}_{t \in T}$. A set of m-representable Boolean algebras is given for which the minimal $(\mathfrak{m}-\mathfrak{n})$ product is not $m$-representable and for which there is no smallest $(m-n)$ product.

These problems have been proposed by R. Sikorski (see [2]). Concerning $\left\{\mathfrak{H}_{t}\right\}_{t \in T}$, it is assumed throughout that each of these algebras has at least four elements. $\mathfrak{m}$ and $\mathfrak{n}$ will always denote infinite cardinals with $\mathfrak{n} \leqq \mathfrak{m}$. All definitions are taken from [2]. An $\mathrm{m}$-homomorphism is a homomorphism that is conditionally $\mathrm{m}$-complete. We denote the class of $(\mathfrak{m}-\mathfrak{n})$ products of $\left\{\mathfrak{A}_{t}\right\}_{t \in T}$ by $\boldsymbol{P}_{\mathfrak{n}}$ and the class of $(\mathfrak{M}-0)$ products by $\boldsymbol{P}$. Let $\left\{\left\{i_{t}\right\}_{t \in T}, \mathscr{B}\right\}$ and $\left\{\left\{j_{t}\right\}_{t \in T}\right.$, $\left.\mathfrak{S}\right\}$ be elements of $\boldsymbol{P}$. We say that

$$
\left\{\left\{i_{t}\right\}_{t \in T}, \mathscr{B}\right\} \leqq\left\{\left\{j_{t}\right\}_{t \in T}, \mathfrak{S}\right\}
$$

provided there is an $n$ thomomorphism $h$ from $\mathfrak{C}$ onto $\mathscr{B}$ such that $h \circ j_{t}=i_{t}$ for $t \in T$. The relation "@" is a quasi-ordering of $\boldsymbol{P}$. Two $(\mathfrak{m}-0)$ products are isomorphic if each is $\leqq$ to the other.

The particular product, $\left\{\left\{g_{t}^{*}\right\}_{t \in T}, \mathscr{F}_{n}^{*}\right\}$ of $\left\{\mathfrak{H}_{t}\right\}_{t \in T}$ mentioned above is defined as follows. For each $t \in T$ let $X_{t}$ be the Stone space of $\mathfrak{A}_{t}$ and let $g_{t}$ be an isomorphism from $\mathfrak{A}_{t}$ onto the field $\mathscr{F}_{t}$ of all open and closed subsets of $X_{t}$. Let $X$ be the Cartesian product of the sets $X_{t}$, and for each $t \in T$ and each $b \in \mathfrak{H}_{t}$, set

$$
g_{i}^{*}(b)=\left[x \in X: x(t) \in g_{t}(b)\right\} .
$$

Let $G_{11}$ be the set of all subsets $a$ of $X$ which satisfy the following condition:

$$
a=\bigcap_{t \in S} g_{t}^{*}\left(b_{t}\right) \text { where } b_{t} \in \mathfrak{U}_{i}, S \subseteq T \text { and } \overline{\bar{S}} \leqq \mathfrak{H} \text {. }
$$

Finally, let $\mathscr{F}_{\mathfrak{l}}^{*}$ be the field of subsets of $X$ which is generated by $G_{n}$. 
$\mathscr{F}_{\mathfrak{n}} *$ is a base for the $\mathfrak{n}$-topology on $X . g_{t}^{*}$ is a complete isomorphism from $\mathfrak{U}_{t}$ into $\mathscr{F}_{\mathfrak{n}}^{*}$. The set $\left\{g_{t}^{*}\left(\mathfrak{H}_{t}\right)\right\}$, of subalgebras, is $\mathfrak{n}-$ independent.

A Boolean $(\mathfrak{n}-\mathfrak{n})$ product $\left\{\left\{i_{t}\right\}_{t \in T}, \mathscr{B}\right\}$ is said to belong to $\boldsymbol{E}_{\mathfrak{n}}$ if and only if there is an m-isomorphism $h$ (from $\mathscr{F}_{\mathfrak{n}}^{*}$ into $\mathscr{B}$ ) such that $\{h, \mathscr{B}\}$ is an m-extension of $\mathscr{F}_{\mathrm{n}}^{*}$ and for each $t \in T h \circ g_{t}^{*}=i_{t}$.

For every m-extension $\{h, \mathscr{B}\}$ of $\mathscr{F}_{\mathfrak{n}}{ }^{*},\left\{\left\{h \circ g_{t}^{*}\right\}_{t \in T}, \mathscr{B}\right\} \in \boldsymbol{E}_{\mathfrak{n}}$. Clearly $\boldsymbol{E}_{\mathfrak{n}} \subseteq \boldsymbol{P}_{\mathfrak{n}}$ and $\boldsymbol{E}_{\mathfrak{n}}$ is not empty. m-extensions of $\mathscr{T}_{\mathfrak{n}} *$ seem to provide the most natural examples of Boolean $(\mathfrak{m}-\mathfrak{n})$ products.

1. Lemma 1.1. Let $\left\{\mathscr{B}_{t}\right\}_{t \in T}$ be an $\mathfrak{n}$-independent set of subalgebras of a Boolean algebra $\mathfrak{Y}$ and let $S$ and $S^{\prime}$ be subsets of $T$ with $\overline{\bar{S}} \leqq \mathfrak{n}$ and $\overline{\bar{S}}^{\prime} \leqq \mathfrak{n}$. For each $t$ let $a_{t}$ and $b_{t}$ be nonzero elements of $\mathscr{B}_{t}$. Then

(i ) $\prod_{t \in S}^{\mathfrak{H}} a_{t} \leqq \prod_{t \in S}^{\mathfrak{H}} b_{t}$ if and only if $a_{t} \leqq b_{t}$ for each $t \in S$;

(ii) $\prod_{t \in S}^{\mathfrak{H}} a_{t}=\prod_{t \in S^{\prime}}^{\mathfrak{H}} b_{t}$ implies that $a_{t}=b_{t}$ for $t \in S \cap S^{\prime}, a_{t}=1$ for $t \in S-S^{\prime}$, and $b_{t}=1$ for $t \in S^{\prime}-S$.

Proof. (i) Assume that for some $t_{0} \in S, a_{t_{0}} b_{t_{0}}$. Define

$$
C_{t}=\left\{\begin{array}{l}
a_{t} \text { if } t \in S \text { and } t \neq t_{0}, \\
a_{t_{0}} \cdot\left(-b_{t_{0}}\right) \text { if } t=t_{0} .
\end{array}\right.
$$

Set $c=\prod_{t \in S}^{\mathfrak{H}} c_{t}$, and note that $c \neq 0, c \leqq \prod_{t \in S}^{\mathfrak{A}} a_{t}$, and $c \cdot \prod_{t \in S}^{\mathcal{H}} b_{t}=0$. The converse is clear.

To prove (ii) we define

$$
x_{t}=\left\{\begin{array}{l}
a_{t} \text { if } t \in S, \\
1 \text { if } t \in S^{\prime}-S ;
\end{array} \text { and } y_{t}=\left\{\begin{array}{l}
b_{t} \text { if } t \in S^{\prime} \\
1 \text { if } t \in S-S^{\prime} .
\end{array}\right.\right.
$$

Now

$$
\prod_{t \in S \cup S^{\prime}}^{\mathscr{H}} x_{t}=\prod_{t \in S}^{\mathscr{H}} a_{t}=\prod_{t \in S^{\prime}}^{\mathscr{A}} b_{t}=\prod_{t \in S}^{\mathscr{H}} y_{t}
$$

and (ii) follows from (i).

Lemma 1.2. Let $\left\{\mathscr{B}_{t}\right\}_{t \in T}$ be an $\mathfrak{n}$-independent set of subalgebras of a Boolean algebra $\mathfrak{i}$. Let $G$ be the set of all meets $\prod_{t \in S}^{\mathfrak{H}} a_{t}$ such that $S \leqq T, \overline{\bar{S}} \leqq \mathfrak{n}$, and for each $t \in S a_{t}$ is a nonzero element of $\mathscr{B}_{t}$. Assume further that $G$ generates $\mathfrak{A}$. Then $G$ is dense in $\mathfrak{A}$.

Proof. First note that for $g, g^{\prime} \in G$ either $g \cdot g^{\prime}=0$ or else $g \cdot g^{\prime} \in G$. Thus every nonzero element of $\mathfrak{A}$ is a finite join of elements of the form $g \cdot \prod_{i<k}^{\mathfrak{R}}\left(-g_{i}\right)$ with $g, g_{i} \in G$ and $k$ finite. (This notation is intended 
to include the special cases $g$ and $-g$.) Now suppose $g \cdot \prod_{i<k}^{\mathfrak{A}}\left(-g_{i}\right) \neq 0$, so that $g \$ \sum_{i<k} g_{i}$. We write a common form $g=\prod_{t \in S}^{\mathfrak{A}} a_{t}$, and for each $i<k g_{i}=\prod_{t \in S}^{\mathfrak{A}} a_{i, t}$ where $S \subseteq T, \overline{\bar{S}} \leqq \mathfrak{n}$, and for each $t \in S a_{t}$ and $a_{i, t}$ are nonzero elements of $\mathscr{B}_{t}$. Since $k$ is finite every Boolean algebra is $(k-\mathfrak{n}$ )-distributive (see [2], p. 62). We have

$$
\prod_{t \in S} a_{t} \nRightarrow \sum_{i<k} \prod_{t \in S} a_{i, t}=\prod_{\psi \in S^{k}} \sum_{i<k} a_{i, \psi(i)} .
$$

(Here $S^{k}$ denotes the set of all functions from $k=\{0,1, \cdots, k-1\}$ into $S$.) Choose $\phi \in S^{k}$ such that $\prod_{t \in S} a_{t} \sum_{i<k} a_{i, \phi(i)}$. We have, for each $s \in\{\dot{\phi}(i): i<k\}, a_{s} \neq \sum_{\phi(i)=s} a_{i, \phi(i)}$. Define

$$
b_{t}=\left\{\begin{array}{l}
a_{t} \text { if } t \in S-\{\phi(i): i<k\} \\
a_{t} \cdot-\sum_{\phi(i)=t} a_{i, \phi(i)} \text { if } t \in\{\phi(i): i<k\} .
\end{array}\right.
$$

Finally let $b=\prod_{t \in S}^{\mathfrak{A}} b_{t}$. Clearly $b \neq 0, b \in G$ and $b \leqq g$. For each $t \in\{\dot{\phi}(i): i<k\}, b_{t} \cdot \sum_{\phi(i)=t} a_{i, \phi(i)}=0$, so that $b \cdot \sum_{i<k} a_{i, \phi(i)}=0$. It follows that $b \cdot \sum_{i<k} g_{i}=0$, hence $b \leqq g \cdot \prod_{i<k}\left(-g_{i}\right)$.

COROLlaRY 1.3. If $\overline{\bar{S}}>\mathfrak{n}$, and for each $t \in S, a_{t} \neq 1$, then $\prod_{t \in S}^{\mathscr{A}} a_{t}=0$.

Theorem 1.4. Let $\left\{\left\{i_{t}\right\}_{t \in T}, \mathscr{B}\right\} \in \boldsymbol{P}_{\mathrm{n}}$. There is one and only one isomorphism $h_{\mathfrak{n}}$ from $\mathscr{F}_{\mathfrak{n}}{ }^{*}$ into $\mathscr{B}$ which satisfies the following completeness condition:

$$
\begin{aligned}
& h_{\mathfrak{n}}\left(\prod_{t \in S}^{\mathscr{F}_{\mathfrak{n}}^{*}} g_{t}^{*}\left(a_{t}\right)\right)=\prod_{t \in S}^{\infty} i_{t}\left(a_{t}\right) \text { whenever } S \leqq T, \overline{\bar{S}} \leqq \mathfrak{H}, \\
& a_{t} \in \mathfrak{U}_{t} \text { and } a_{t} \neq 0 .
\end{aligned}
$$

Proof. Let $G$ be the set of all meets $\prod_{t \in S}^{\mathscr{S}} i_{t}\left(a_{t}\right)$ such that $S \leqq T$, $\overline{\bar{S}} \leqq \mathfrak{n}$, each $a_{t} \in \mathfrak{N}_{t}$ and $a_{t} \neq 0$. Let $\mathfrak{A}$ be the subalgebra of $\mathscr{B}$ which is generated by $G$. For $\prod_{t \in S}^{\mathscr{O}} i_{t}\left(a_{t}\right) \in G$ it is clear that $\prod_{t \in S}^{\mathscr{R}} i_{t}\left(a_{t}\right)=$ $\Pi_{t \in S}^{\mathfrak{A}} i_{t}\left(a_{t}\right)$. By Lemma 1.2 $G$ is dense in $\mathfrak{2}$. Also $G_{\mathfrak{n}}$ is dense in $\mathscr{F}_{\mathfrak{n}}{ }^{*}$. For $a \in G_{\mathfrak{n}}$ write $a=\bigcap_{t \in S} g_{t}^{*}\left(a_{t}\right)=\prod_{t \in S}^{\widetilde{F}_{\mathfrak{n}}^{*}} g_{t}^{*}\left(a_{t}\right)$. Define $h(a)=\prod_{t \in S}^{\mathfrak{N}} i_{t}\left(a_{t}\right)$. It is easily seen, using Lemma 1.1, that

(i) $h$ is a one to one function from $G_{\mathfrak{n}}$ onto $G$;

(ii) for $a, b \in G_{\mathfrak{n}}, a \leqq b$ if and only if $h(a) \leqq h(b)$.

It follows (see [2], p. 37) that $h$ can be extended to an isomorphism $h_{\mathfrak{n}}$ from $\mathscr{F}_{\mathfrak{n}} *$ onto $\mathfrak{A}$. $h_{\mathfrak{n}}$ is uniquely determined by condition (c) because $G_{\mathrm{n}}$ generates $\mathscr{F}_{\mathrm{nt}}{ }^{*}$.

CoRollary 1.5. The product $\left\{\left\{i_{t}\right\}_{t \in T}, \mathscr{P}\right\} \in \boldsymbol{E}_{\mathfrak{n}}$ if and only if $h_{\mathfrak{n}}$ is $\mathrm{m}$-complete. 
Proof. Let $\left\{\left\{i_{t}\right\}_{t \in T}, \mathscr{B}\right\} \in \boldsymbol{E}_{\mathrm{n}}$. There is an m-isomorphism $f$ from $\mathscr{F}_{\mathrm{n}}{ }^{*}$ into $\mathscr{B}$ such that for each $t \in T, f \circ g_{t}^{*}=i_{t} . f$ satisfies condition (c) so $f=h_{\mathrm{n}}$.

Corollary 1.6. Assume $\overline{\bar{T}}>\mathfrak{n}$ and that $\mathfrak{m} \geqq \mathfrak{n}^{\prime}>\mathfrak{n}$. Then $\boldsymbol{P}_{\mathfrak{n}^{\prime}} \cap \boldsymbol{E}_{\mathfrak{n}}$ is empty.

Proof. Let $\left\{\left\{i_{t}\right\}_{t \in T}, \mathscr{B}\right\} \in \boldsymbol{P}_{\mathfrak{n}^{\prime}}$. Consider the isomorphism $h_{\mathfrak{n}}$ from $\mathscr{F}_{\mathfrak{n}}^{*}$ into $\mathscr{B}$. Choose $S \subseteq T, \overline{\bar{S}}=\mathfrak{n}^{+}$, and for each $t \in S$ choose $a_{t} \in \mathfrak{U}_{t}$ with $a_{t} \neq 0, a_{t} \neq 1$. By Corollary 1.3

$$
\prod_{t \in S}^{\mathbb{S}_{\mathfrak{m}}^{*}} g_{t}^{*}\left(a_{t}\right)=0 \text {. }
$$

However $0 \neq \prod_{t \in S}^{\mathscr{B}} i_{t}\left(a_{t}\right)=\prod^{3} h_{\mathfrak{n}} \circ g_{t}^{*}\left(a_{t}\right)$ so that $h_{\mathfrak{n}}$ is not m-complete.

There is an interesting contrast between $\boldsymbol{E}_{\mathrm{n}}$ and $\boldsymbol{P}_{\mathfrak{n}^{\prime}}$, (under the hypotheses of Corollary 1.6). Let $\left\{\left\{i_{t}\right\}_{t \in T}, \mathscr{B}\right\}$ and $\left\{\left\{j_{t}\right\}_{t \in T}, \mathfrak{⿷}\right\}$ be elements of $\boldsymbol{P}_{\mathfrak{n}}$ with $\left\{\left\{i_{t}\right\}_{t \in T}, \mathscr{B}\right\} \leqq\left\{\left\{j_{t}\right\}_{t \in T}\right.$, E $\}$. It is known (see [2], p. 179) that if $\left\{\left\{i_{t}\right\}_{t \in T}, \mathscr{B}\right\} \in \boldsymbol{P}_{\mathfrak{n}^{\prime}}$, then $\left\{\left\{j_{t}\right\}_{t \in T}, \mathfrak{C}\right\} \in \boldsymbol{P}_{\mathfrak{n}^{\prime}}$. On the other hand if $\left\{\left\{j_{t}\right\}_{t \in T}, \mathfrak{C}\right\} \in \boldsymbol{E}_{\mathfrak{n}}$ then we have $\left\{\left\{i_{t}\right\}_{t \in T}, \mathscr{B}\right\} \in \boldsymbol{E}_{\mathfrak{n}}$.

Corollary 1.7. Assume $\overline{\bar{T}}>\mathfrak{n}$ and $\mathfrak{m}>\mathfrak{n}$. Then $\boldsymbol{E}_{\mathfrak{n}} \cup \boldsymbol{P}_{\mathfrak{n}+} \neq \boldsymbol{P}_{\mathfrak{n}}$.

Proof. Let $S \subseteq T$ with $\overline{\bar{S}}=\mathfrak{n}^{+}$. Choose, for each $t \in S, d_{t} \in \mathfrak{A}_{t}$ with $d_{t} \neq 0, d_{t} \neq 1$. Let $d=\bigcap_{t \in S} g_{t}^{*}\left(d_{t}\right)$. Let $\mathscr{F}$ be the field of subsets of $X$ which is generated by $\mathscr{F}_{\mathfrak{n}}^{*} \cup\{d\}$. Note that $g_{t}^{*}$ is a complete isomorphism from $\mathfrak{U}_{t}$ into $\mathscr{F}_{\text {. }}$ Let $\{f, \mathfrak{F}\}$ be any m-extension of $\mathscr{F}$. It is easily seen that $\left\{\left\{f \circ g_{t}^{*}\right\}_{t \in T}, \mathfrak{E}\right\} \in \boldsymbol{P}_{\mathrm{n}}$.

Consider the isomorphism $h_{\mathfrak{n}}$ from $\mathscr{F}_{\mathfrak{n}}^{*}$ into (5. $h_{\mathfrak{n}} \circ g_{t}^{*}=f \circ g_{t}^{*}$ for every $t \in T$. By Corollary $1.3 \prod_{t \in S}^{\widetilde{N}} g_{t}\left(d_{t}\right)=0$. However $\prod_{t \in S}^{\stackrel{s}{s}} h_{\mathfrak{n}} \circ g_{t}^{*}\left(d_{t}\right)=$ $f(d) \neq 0$. Thus $h_{\mathrm{n}}$ is not m-complete and $\left\{\left\{f \circ g_{t}^{*}\right\}_{t \in T}, \mathbb{E}\right\} \notin \boldsymbol{E}_{\mathrm{n}}$.

In order to show that $\left\{\left\{f \circ g_{t}^{*}\right\}_{t \in T}, \mathcal{E}\right\} \notin \boldsymbol{P}_{+\mathfrak{n}}$ it suffices to show that $\Pi_{t \in S} f \circ g_{t}^{*}\left(-d_{t}\right)=0$. In particular suppose $b=\prod_{t \in S}^{\mathscr{F}} g_{t}^{*}\left(-d_{t}\right) \neq 0$. Since $b \cdot d=0$ the definition of $\mathscr{F}$ enables us to write $b=\mathbf{U}_{t \in S} b_{1}$. $g_{t}^{*}\left(-d_{t}\right)$ with $b_{1} \in \mathscr{F}_{\mathrm{n}}{ }^{*}$. Choose $t_{0} \in S$ such that $0 \neq b_{1} \cdot g_{t_{0}}^{*}\left(-d_{t_{0}}\right) \leqq b$. By Lemma 1.2 there is a nonzero element $a=\bigcap_{t \in S^{\prime}} g_{t}^{*}\left(a_{t}\right)$ of $G_{\mathrm{n}}$ such that $a \leqq b_{1} \cdot g_{i_{0}}^{*}\left(-d_{t_{0}}\right)$. Now $\overline{S^{\prime}} \leqq \mathfrak{n}$ and $\overline{S^{\prime}}=\mathfrak{n}^{+}$and it follows that $a \leqq b$. Thus $\prod_{t \in S}^{\mathscr{F}} g_{t}^{*}\left(-d_{t}\right)=0$ and since $f$ is $m$-complete, $\prod_{t \in S}^{\mathbb{S}} f \circ g_{t}^{*}\left(-d_{t}\right)=0$.

We now consider the case $\mathfrak{n}=\mathfrak{m}$. It is known that $\boldsymbol{E}_{\mathfrak{m}} \neq \boldsymbol{P}_{\mathfrak{m}}$ if $\mathfrak{m}=\boldsymbol{N}_{0}$ (see [2], p. 190, Example D). In this example $T$ is the two element set $\{1,2\}, \mathfrak{N}_{1}$ and $\mathfrak{U}_{2}$ are $\sigma$-complete Boolean algebras which satisfy the $\sigma$-chain condition. The Boolean $\sigma$-product $\left\{\left\{i_{1}, i_{2}\right\}, \mathscr{B}\right\}$ is such that the subalgebra $\mathscr{B}_{0}$ of $\mathscr{B}$ which is generated by $i_{1}\left(\mathfrak{A}_{1}\right) \cup i_{2}\left(\mathfrak{A U}_{2}\right)$ 
is not a $\sigma$-regular subalgebra of $\mathscr{B}$. Let $\{f, \mathfrak{E}\}$ be any m-extension of $\mathscr{B}$. It follows, using the $\sigma$-chain condition on $\mathfrak{A}_{1}$ and $\mathfrak{A}_{2}$, that $\left\{\left\{f \circ i_{1}, f \circ i_{2}\right\},(5) \in \boldsymbol{P}_{\mathfrak{m}}\right.$. Since $T$ is finite $\left\{\left\{g_{1}^{*}, g_{2}^{*}\right\}, \mathscr{F}_{m}^{*}\right\}$ is the Boolean product of $\left\{\mathfrak{A}_{1}, \mathfrak{A}_{2}\right\}$. Let $h$ be the homomorphism from $\mathscr{F}_{\mathfrak{m}}{ }^{*}$ into $\mathscr{B}$ such that $h \circ g_{1}^{*}=i_{1}$ and $h \circ g_{2}^{*}=i_{2}$. Then $h$ is an isomorphism from $\mathscr{F}_{\mathfrak{m}}{ }^{*}$ onto $\mathscr{B}_{0}$. Consider the isomorphism $h_{\mathfrak{m}}$, from $\mathscr{F}_{\mathfrak{m}}{ }^{*}$ into $\mathfrak{E}$, given by Theorem 1.4. $h_{\mathfrak{m}}=f \circ h$ since they agree on $g_{1}^{*}\left(\mathfrak{A}_{1}\right) \cup g_{2}^{*}\left(\mathfrak{H}_{2}\right) . h_{\mathfrak{n}}$ is not m-complete because $f\left(\mathscr{B}_{0}\right)$ is not m-regular in $\mathfrak{E}$. Thus $\left\{\left\{f \circ i_{1}\right.\right.$, $\left.\left.f \circ i_{2}\right\}, \mathfrak{⿷}\right\} \notin \boldsymbol{E}_{\mathfrak{m}}$. We give a simple for the case $m \geqq 2^{\aleph_{0}}$.

Example 1.8. Assume $m \geqq 2^{\aleph} 0$ and let $T$ be a set of power $\aleph_{0}$. For each $t \in T$ let $\mathfrak{U}_{t}$ be a Boolean algebra having exactly four elements. Let $\mathscr{P}$ be the free Boolean m-algebra on $\aleph_{0} \mathrm{mt}$-generators, $\left(D_{t}: t \in T\right\}$. $\mathscr{B}$ is not m-representable (see [2], p. 134). For each $t \in T$ choose $d_{t}$ to be one of the atoms of $\mathfrak{A}_{t}$. Let $i_{t}$ be the isomorphism from $\mathfrak{N}_{t}$ into $\mathscr{B}$ such that $i_{t}\left(d_{t}\right)=D_{t}$. Then $\left\{\left\{i_{t}\right\}_{t \in T}, \mathscr{B}\right\} \in \boldsymbol{P}_{\mathfrak{m}}$. By Lemma $1.2 \mathscr{F}_{\mathrm{m}}{ }^{*}$ is atomic, the atoms being all sets of the form $\bigcap_{t \in T} g_{t}^{*}\left(a_{t}\right)$, where for each $t \in T a_{t}$ is an atom of $\mathfrak{U}_{t}$. Denote the set of atoms of $\mathscr{F}_{\mathrm{nt}}{ }^{*}$ by $\left\{C_{r}: r \in R\right\}$, then $\overline{\bar{R}}=2^{\aleph_{0}}$. We consider the isomorphism $h_{\mathfrak{n}}$ from $\mathscr{F}_{\mathfrak{n}}{ }^{*}$ into $\mathscr{B}$. For each $r \in R, h_{\mathfrak{m}}\left(c_{r}\right)$ is an atom of $\mathscr{B}$. To show this we define

$$
\mathfrak{U}=\left\{b \in \mathscr{B}: \text { for each } r \in R \text { either } b \cdot h_{\mathfrak{m}}\left(c_{r}\right)=0 \text { or } h_{\mathfrak{m}}\left(c_{r}\right) \leqq b\right\} .
$$

It is easily seen that $\mathfrak{A}$ is an m-subalgebra of $\mathscr{P}$ which includes $\left\{D_{t}: t \in T\right\}$. Hence $\mathfrak{A}=\mathscr{B}$. Finally, $h_{\mathfrak{m}}$ is not $\mathfrak{m}$-complete. For otherwise $\sum_{r \in R} h_{\mathrm{nt}}\left(c_{r}\right)=1$, and $\mathscr{B}$ would be atomic and hence isomorphic to an $m$-field of sets.

2. We now consider the problem of the existence of a smallest element of $\boldsymbol{P}$, relative to the quasi-ordering "ฏ". A minimal element of $\boldsymbol{P}$ always exists and can be constructed as follows. Let $\left\{\left\{f_{t}\right\}_{t \in T}\right.$, $\left.\sqrt{ }\right\}$ be a Boolean product of $\left\{\mathfrak{A}_{t}\right\}_{t \in T}$ and let $\{h, \mathscr{B}\}$ be an m-completion of c. Then $\left\{\left\{h \circ f_{t}\right\}_{t \in T}, \mathscr{B}\right\}$ is a minimal element of $\boldsymbol{P}$. We shall show that this product need not be a smallest element of $\boldsymbol{P}$. Hence $\boldsymbol{P}$ need not have a smallest element.

Example 2.1. Let $\mathfrak{m}$ be any infinite cardinal. Let $\overline{\bar{T}}=\boldsymbol{\aleph}_{0}$ and suppose that for each $t \in T \mathfrak{A}_{t}$ is a four element Boolean algebra. For each $t \in T$ choose $a_{t}$ to be one of the atoms of $\mathfrak{A}_{t}$. $\mathbb{E}$ is a free Boolean algebra of power $\boldsymbol{\aleph}_{0}$, one set of free generators being $\left\{f_{t}\left(a_{t}\right): t \in T\right\}$. $\mathscr{B}$ has a countable dense subset, in particular $\mathscr{B}$ satisfies the countable chain condition. Thus $\mathscr{B}$ is complete. It follows that $\mathscr{B}$ is isomorphic to the quotient algebra $\mathscr{F} / \Delta_{0}$ where $\mathscr{F}$ is the $\sigma$-field 
of Borel subsets of the unit interval $I=\{x: 0<x \leqq 1\}$ of real numbers and $\Delta_{0}$ is the ideal consisting of those Borel sets which are of the first category.

To show that $\left\{\left\{h \circ f_{t}\right\}_{t \in T}, \mathscr{B}\right\}$ is not a smallest element of $\boldsymbol{P}$ we construct another (m-0) product as follows. Let $G$ be the set of all halfopen intervals of the form $\{x: 0<x \leqq r\}$ such that $r$ is rational and $0<r \leqq 1$. $\mathscr{F}$ is $\sigma$-generated by $G$. The subalgebra $\mathscr{F}_{0}$ of $\mathscr{F}$ which is generated by $G$ is denumerable and atomless. Hence $\mathscr{F}_{0}$ is isomorphic to (5 (see [1], p. 54). Let $g$ be an isomorphism from (5 onto $\mathscr{F}_{0}$. Let $\Delta_{1}$ be the ideal of $\mathscr{F}$ consisting of those Borel sets having Lebesgue measure 0 . We note that $\mathscr{F}_{0} \cap \Delta_{1}=\{0\}$. Finally for each $t \in T$ let $h_{t}$ be the isomorphism from $\mathfrak{A}_{t}$ into $\mathscr{F} / \Delta_{1}$ defined by $h_{t}\left(a_{t}\right)=\left[g \circ f_{t}\left(a_{t}\right)\right] \Delta_{1}$. It is easily seen that $\left\{\left\{h_{t}\right\}_{t \in T}, \mathscr{F} / \Delta_{1}\right\} \in \boldsymbol{P}$.

Now assume $\left\{\left\{h \circ f_{t}\right\}_{t \in T}, \mathscr{B}\right\} \leqq\left\{\left\{h_{t}\right\}_{t \in T}, \mathscr{F} / \Delta_{1}\right.$. Then there is an m-homomorphism $p$ from $\mathscr{F} / \Delta_{1}$ onto $\mathscr{F} / \Delta_{0}$. Since $\mathscr{F} / \Delta_{1}$ satisfies the countable chain condition the kernel of $p$ is a principal ideal. $\mathscr{F} / \Delta_{0}$ is isomorphic to a principal ideal of $\mathscr{F} / \Delta_{1}$. However $\mathscr{F} / \Delta_{1}$ is homogeneous (see [2], p. 105). Thus $\mathscr{F} / \Delta_{0}$ is isomorphic to $\mathscr{F} / \Delta_{1}$, which is a contradiction.

Next we consider the problem of the existence of a smallest element of $\boldsymbol{P}_{\mathfrak{n}}$. Let $\{g, \mathscr{B}\}$ be an m-completion of $\mathscr{F}_{\mathfrak{n}}{ }^{*}$. Then $\left\{\left\{g \circ g_{t}^{*}\right\}_{t \in T}, \mathscr{B}\right\}$ is a minimal element of $\boldsymbol{P}_{\mathrm{n}}$. Also it is known (see [2], p. 183) that if all the $\mathfrak{A}_{t}$ are m-representable then there is an (nt-n) product $\left\{\left\{i_{t}\right\}_{t \in T}\right.$, $\left.\sqrt{5}\right\}$ for which $\mathbb{E}$ is m-representable. We give an example of $\left\{\mathfrak{H}_{t}\right\}_{t \in T}$ for which $\mathscr{B}$ is not mt-representable and $\left\{\left\{g \circ g_{t}^{*}\right\}_{t \in T}, \mathscr{B}\right\}$ is not a smallest element of $\boldsymbol{P}_{\mathrm{n}}$.

EXAMPLE 2.2. Assume that $m \geqq 2^{(\mathfrak{n}+)}$. Let $\overline{\bar{T}}=\mathfrak{n}^{+}$and for each $t \in T$ let $\mathfrak{A}_{t}$ be a four element Boolean algebra. We show that $\mathscr{B}$ is not $\mathfrak{n}^{+}$-distributive. Choose, for each $t \in T, a_{t}$ to be one of the atoms of $\mathfrak{H}_{t}$. Then

$$
\prod_{t \in T}^{\mathscr{R}}\left(g \circ g_{t}^{*}\left(a_{t}\right)+-g \circ g_{t}^{*}\left(a_{t}\right)\right)=1 .
$$

However for each function $\eta \in H^{T}$ (here $H=\{+1,-1\}$ ) we have

$$
\prod_{t \in T}^{\mathscr{T}_{\mathrm{n}}^{*}} \eta(t) \cdot g_{t}^{*}\left(a_{t}\right)=0 .
$$

This follows from Corollary 1.3. Thus $\prod_{t \in T}^{\infty} \eta(t) \cdot g \circ g_{t}^{*}\left(a_{t}\right)=0$. This proves $\mathscr{B}$ is not $\mathfrak{n t}^{+}$-distributive and hence not $\mathfrak{n t}$-representable.

To show that $\left\{\left\{g \circ g_{t}^{*}\right\}_{t \in T}, \mathscr{B}\right\}$ is not a smallest element of $\boldsymbol{P}_{\mathfrak{n}}$, let $\left\{\left\{i_{t}\right\}_{t \in T}\right.$, $\left.\mathfrak{E}\right\}$ be any (m-n) product of $\left\{\mathfrak{A}_{t}\right\}_{t \in T}$ such that $\mathbb{E}$ is $\mathfrak{m}-$ representable. $\mathscr{B}$ is not an m-homomorphic image of $\mathfrak{E}$. Thus the inequality 


$$
\left\{\left\{g \circ g_{t}^{*}\right\}_{t \in T}, \mathscr{B}\right\} \leqq\left\{\left\{i_{t}\right\}_{t \in T}, \mathbb{C}\right\}
$$

does not hold.

\section{REFERENCES}

1. P. H. Dwinger, Introduction to Boolean algebras, Wurzburg, 1961.

2. R. Sikorski, Boolean algebras, Second Edition, Springer Verlag, 1964.

Received July 19, 1968.

UNIVERSITY OF WYOMING 



\title{
PACIFIC JOURNAL OF MATHEMATICS
}

\author{
EDITORS
}

\author{
H. ROYDEN \\ Stanford University \\ Stanford, California \\ RICHARD PIERCE \\ University of Washington \\ Seattle, Washington 98105
}

\author{
J. DUGUNDJI \\ Department of Mathematics \\ University of Southern California \\ Los Angeles, California 90007 \\ BASIL GORDON \\ University of California \\ Los Angeles, California 90024
}

\section{ASSOCIATE EDITORS}

E. F. BECKENBACH
B. H. NeumanN

F. WOLF
K. YoshidA

\section{SUPPORTING INSTITUTIONS}

\author{
UNIVERSITY OF BRITISH COLUMBIA \\ CALIFORNIA INSTITUTE OF TECHNOLOGY \\ UNIVERSITY OF CALIFORNIA \\ MONTANA STATE UNIVERSITY \\ UNIVERSITY OF NEVADA \\ NEW MEXICO STATE UNIVERSITY \\ OREGON STATE UNIVERSITY \\ UNIVERSITY OF OREGON \\ OSAKA UNIVERSITY \\ UNIVERSITY OF SOUTHERN CALIFORNIA
}

\author{
STANFORD UNIVERSITY \\ UNIVERSITY OF TOKYO \\ UNIVERSITY OF UTAH \\ WASHINGTON STATE UNIVERSITY \\ UNIVERSITY OF WASHINGTON

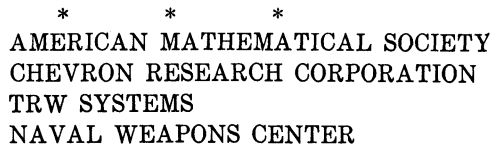

The Supporting Institutions listed above contribute to the cost of publication of this Journal, but they are not owners or publishers and have no responsibility for its content or policies.

Mathematical papers intended for publication in the Pacific Journal of Mathematics should be in typed form or offset-reproduced, double spaced with large margins. Underline Greek letters in red, German in green, and script in blue. The first paragraph or two must be capable of being used separately as a synopsis of the entire paper. It should not contain references to the bibliography. Manuscripts, in duplicate if possible, may be sent to any one of the four editors. Please classify according to the scheme of Math. Rev. 36, 1539-1546. All other communications to the editors should be addressed to the managing editor, Richard Arens, University of California, Los Angeles, California, 90024.

50 reprints are provided free for each article; additional copies may be obtained at cost in multiples of 50 .

The Pacific Journal of Mathematics is published monthly. Effective with Volume 16 the price per volume (3 numbers) is $\$ 8.00$; single issues, $\$ 3.00$. Special price for current issues to individual faculty members of supporting institutions and to individual members of the American Mathematical Society: $\$ 4.00$ per volume; single issues $\$ 1.50$. Back numbers are available.

Subscriptions, orders for back numbers, and changes of address should be sent to Pacific Journal of Mathematics, 103 Highland Boulevard, Berkeley, California, 94708.

PUBLISHED BY PACIFIC JOURNAL OF MATHEMATICS, A NON-PROFIT CORPORATION

Printed at Kokusai Bunken Insatsusha (International Academic Printing Co., Ltd.), 7-17, Fujimi 2-chome, Chiyoda-ku, Tokyo, Japan. 


\section{Pacific Journal of Mathematics}

\section{Vol. 31, No. $3 \quad$ BadMonth, 1969}

George E. Andrews, On a calculus of partition functions .................. 555

Silvio Aurora, A representation theorem for certain connected rings ............ 563

Lawrence Wasson Baggett, A note on groups with finite dual spaces ............. 569

Steven Barry Bank, On majorants for solutions of algebraic differential equations in regions of the complex plane ............................... 573

Klaus R. Bichteler, Locally compact topologies on a group and the corresponding continuous irreducible representations ......................... 583

Mario Borelli, Affine complements of divisors ....................... 595

Carlos Jorge Do Rego Borges, A study of absolute extensor spaces ............. 609

Bruce Langworthy Chalmers, Subspace kernels and minimum problems in Hilbert

spaces with kernel function ...................................... 619

John Dauns, Representation of L-groups and F-rings................. 629

Spencer Ernest Dickson and Kent Ralph Fuller, Algebras for which every

indecomposable right module is invariant in its injective envelope ...........

Robert Fraser and Sam Bernard Nadler, Jr., Sequences of contractive maps and fixed

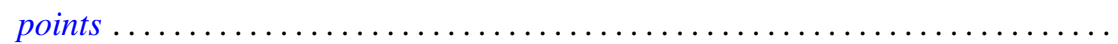

Judith Lee Gersting, A rate of growth criterion for universality of regressive

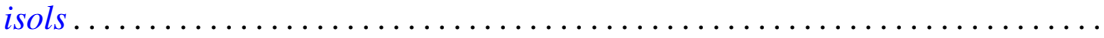

Robert Fred Gordon, Rings in which minimal left ideals are projective ............

Fred Gross, Entire functions of several variables with algebraic derivatives at certain algebraic points

W. Charles (Wilbur) Holland Jr. and Stephen H. McCleary, Wreath products of ordered permutation groups .........................

W. J. Kim, The Schwarzian derivative and multivalence .................. 717

Robert Hamor La Grange, Jr., On $(\mathrm{m}-\mathrm{n})$ products of Boolean algebras ......... 725

Charles D. Masiello, The average of a gauge ........................ 733

Stephen H. McCleary, The closed prime subgroups of certain ordered permutation

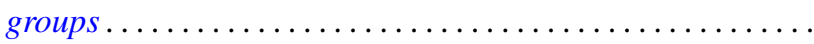

Richard Roy Miller, Gleason parts and Choquet boundary points in convolution measure algebras ...............................

Harold L. Peterson, Jr., On dyadic subspaces ........................ 773

Derek J. S. Robinson, Groups which are minimal with respect to normality being intransitive........................................... 777

Ralph Edwin Showalter, Partial differential equations of Sobolev-Galpern type . . . 787

David Slepian, The content of some extreme simplexes ................... 795

Joseph L. Taylor, Noncommutative convolution measure algebras ............. 809

B. S. Yadav, Contractions of functions and their Fourier series ............... 827

Lindsay Nathan Childs and Frank Rimi DeMeyer, Correction to automorphisms of separable algebras" ....................... 833

Moses Glasner and Richard Emanuel Katz, Correction to: "Function-theoretic degeneracy criteria for Riemannian manifolds".............

Satish Shirali, Correction to: "On the Jordan structure of complex Banach

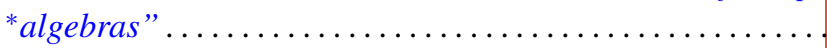

